\title{
A new expression to predict secant rotational stiffness of spudcan in undrained soils
}

\author{
Wenlong $\operatorname{Lin}^{1, *}$ \\ ${ }^{1}$ School of Civil Engineering, Chongqing University, Chongqing 400045, China
}

\begin{abstract}
The nonlinear behavior of spudcan foundation will lead to the decrease of the rotational stiffness of the spudcan, leading to the increase of the stress at the critical member of the offshore jack-up drilling platform. Secant rotational stiffness is used to represent the value of rotational stiffness of linear foundation model when the soil changes from elastic to elasto-plastic and then to plastic. In this paper, the "wished inplace" small strain finite element analysis (SSFE) analysis is used to simulate the load-displacement response of spudcans pre-embedded in the plastic soil, thus calculating the secant rotational stiffness of spudcans. New expressions of failure ratio and secant rotational stiffness are proposed with the coupling effect of horizontal force and moment taken into account.
\end{abstract}

\section{Introduction}

Rotational stiffness is a vital part in the evaluation of the fixity of spudcan foundations, which is significant for the structural analysis of jack-up platforms. Linear and nonlinear foundation model can be used to evaluate the fixity of spudcan foundations. However, it is difficult to establish a nonlinear foundation model, because it is necessary to consider not only the nonlinear constitutive law of soil, but also to study the contact damage that may occur at the interface between soil and foundation [1,2]. In addition, it is difficult to describe these rules through expressions. An alternative is to use a linear foundation model, which treats the spudcan as a macroscopic unit and describes the model in terms of forces and displacements [3]. Elastic stiffness and yield envelope are used to describe the behavior of spudcans in elastic and plastic soils respectively. And the secant rotational stiffness is used to describe the nonlinear behavior of the foundation in the process of soil changing from elastic to plastic. The linear foundation is widely used in study of various aspects of spudcans.

Guidelines, such as ISO and SNUME, give the equation describing the secant rotational stiffness of spudcan foundations, which depends on the location of the vertical $(\mathrm{V})$, horizontal $(\mathrm{H})$, moment $(\mathrm{M})$ loading in the yield envelope.

In the previous versions of SNUME [4], sand and clay were separated and two formulas Equation (1) and Equation (2) were proposed to calculate the secant rotational stiffness of spudcan. In a newer version [5], equation (3) is recommended to calculate the secant rotational stiffness, which is put forward by Sintef [6]. The main advantage of equation (3) is that it applies to both sand and clay. The current guideline [7] updated the calculation formula of secant rotational stiffness again, adopting equation (4) proposed by Templeton [8]. Compared with the previous calculation methods, equation (4) can be applied to a variety of soils, and the disadvantage is that the value of $n$ is not clear in many cases. These four equations are listed as follows:

$$
\begin{gathered}
f_{r}=\frac{-r_{f}}{\ln \left(1-r_{f}\right)} \\
f_{r}=1-r_{f} \\
f_{r}=\sqrt{1-r_{f}}+0.1 e^{100\left(r_{f}-1\right)} \\
f_{r}=\frac{(1-n) r_{f}}{\ln \left[\left(1-n r_{f}\right) /\left(1-r_{f}\right)\right]}
\end{gathered}
$$

Where $f_{r}$ is the reduction factor of the secant rotational stiffness of spudcan, and $r_{f}$ is the failure ratio. The failure ratio expression (Equation (5)) used currently is derived from the formula of spudcan yield surface proposed by Templeton (Equation (6)). These two equations are listed below:

$$
\begin{gathered}
r_{f}=\frac{\sqrt{\left(\frac{M}{M_{0}}\right)^{2}+\left(\frac{H}{H_{0}}\right)^{2}}}{\sqrt{16(1-a)\left(\frac{V}{V_{0}}\right)^{2}\left(1-\frac{V}{V_{0}}\right)^{2}+4 a\left(\frac{V}{V_{0}}\right)\left(1-\frac{V}{V_{0}}\right)}} \leq 1 \\
\left(\frac{M}{M_{0}}\right)^{2}+\left(\frac{H}{H_{0}}\right)^{2}-16(1-a)\left(\frac{V}{V_{0}}\right)^{2}\left(1-\frac{V}{V_{0}}\right)^{2}- \\
4 a\left(\frac{V}{V_{0}}\right)\left(1-\frac{V}{V_{0}}\right)=0
\end{gathered}
$$

Where $V_{0}$ is the ultimate vertical bearing capacity of the soil beneath the spudcan, and $H_{0}, M_{0}$ and $a$ can be calculated by the following formulas: $H_{0}=0.12 V_{0}$, $M_{0}=0.075 V_{0}$, and $a=\frac{W}{2.5 D} \leq 1 . W$ is the embedment depth of spudcan, and $\mathrm{D}$ is the spudcan diameter.

However, Equations 5 and 6 do not take into account the coupling effect of horizontal force and moment. Therefore, in this paper, a new expression of failure ratio is proposed to reflect the influence of these two factors by

\footnotetext{
* Corresponding author: lw1996ws@163.com
} 
finite element analysis.

\section{Numerical model}

\subsection{Wished-in-place}

The investigations in this study were conducted using small strain finite analysis approach (namely wished-inplace), which shows great capabilities in solving complex geotechnical problems. The analyses were carried out using commercially software ABAQUS V6.14.

\subsection{Geometry}

In this study, the soil is modelled as a semi-cylindrical lagrangian model and the spudcan is modelled as a rigid body here (figure 1). The soil model with the depth of 6D and the diameter of 8D is discretized to C3D8R elements. The spudcan model is also discretized to C3D8R elements, and the contact with soil adopts "Tie". The load is applied by controlling the displacement of the load reference point (LRP) in Fig. 2. The soil around the spudcan is discretized with a finer mesh with a unit size of $0.02 \mathrm{D}$, while coarser meshes are prescribed far away from the spudcan towards the soil model boundaries.

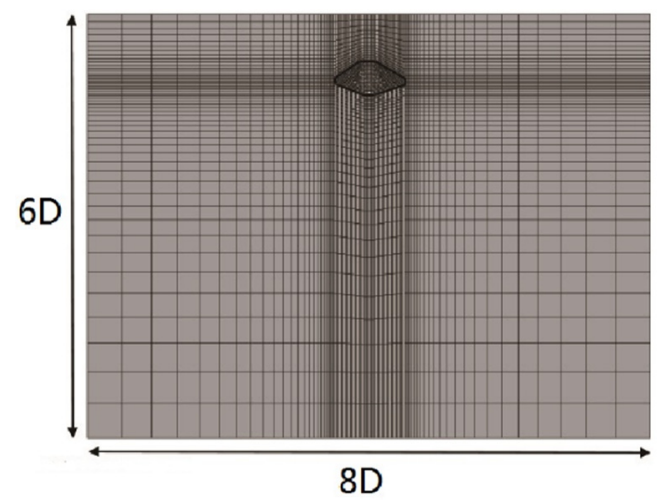

Fig. 1. Geometry and the mesh of the 3D model.

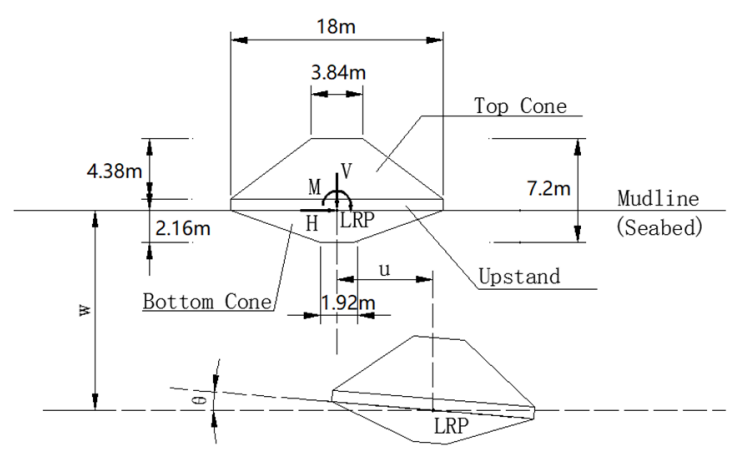

Fig. 2. Spudcan foundation and sign conventions for loads and displacements.

\subsection{Soil profile}

The strength of soil, S_u, increases linearly with depth, and the undrained shear strength can be assumed as:

$$
\mathrm{S}_{u}=\mathrm{S}_{u m}+k z
$$

$\mathrm{S}_{u m}, \mathrm{k}$ and $\mathrm{z}$ are the mudline shear strength, the gradient of soil shear strength and the depth respectively. Poisson's ratio is assumed to be 0.49 here for undrained soils.

\subsection{Simulation step}

The load-displacement response experiment of spudcans is divided into the following two steps: preloading and unloading and then applying the moment to the load reference point. Firstly, a vertical constant force is applied to the LRP point through displacement control test. The constant force is the vertical ultimate bearing capacity of soil. Then unloading is carried out to reduce the vertical constant force to half of the vertical ultimate bearing capacity, and keep the constant force unchanged, and then the spudcan rotate.

\section{Validation}

In order to obtain the coupling effect of horizontal force and moment on the yield surface, probe test is used to verify the envelope surface. In this paper, probe tests of different loading paths were carried out, as is shown in figure 3, and the numerical results obtained were compared with Zhang's work [9]. The results showed good consistency (Figure 4a). Through the comparison of the recommended yield surface by guideline, it is proved that the coupling effect of horizontal force and moment on the yield surface cannot be ignored, as is shown in figure $4 \mathrm{~b}$.

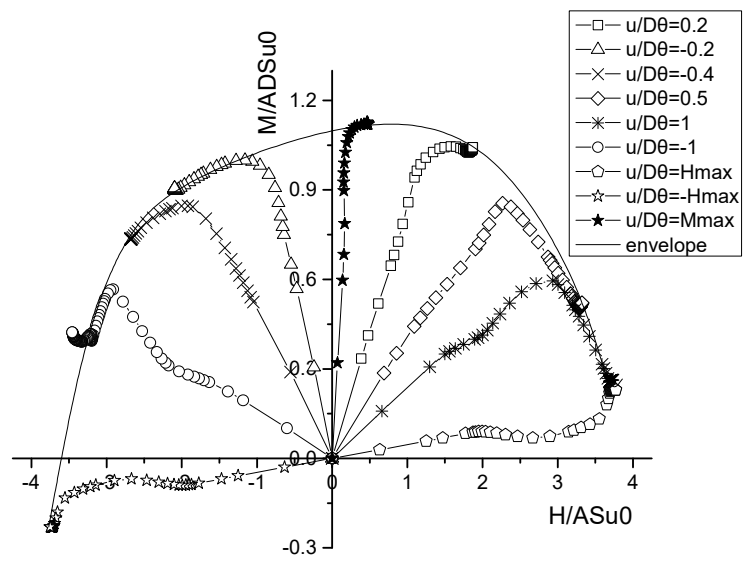

Fig. 3. Probe tests and the HM envelope.

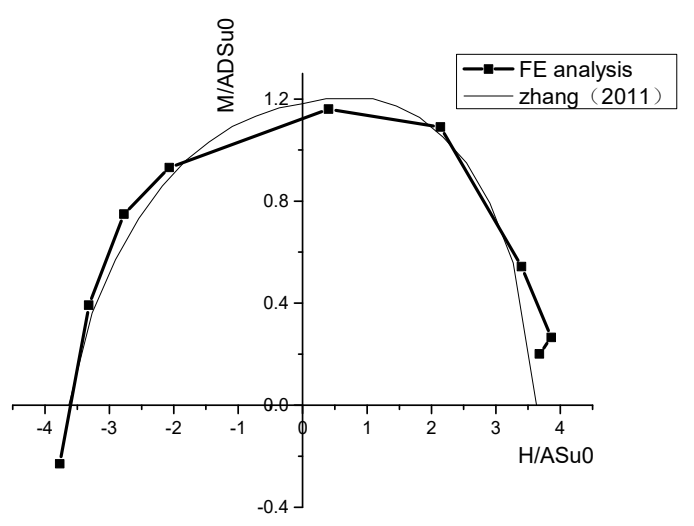

(a) 


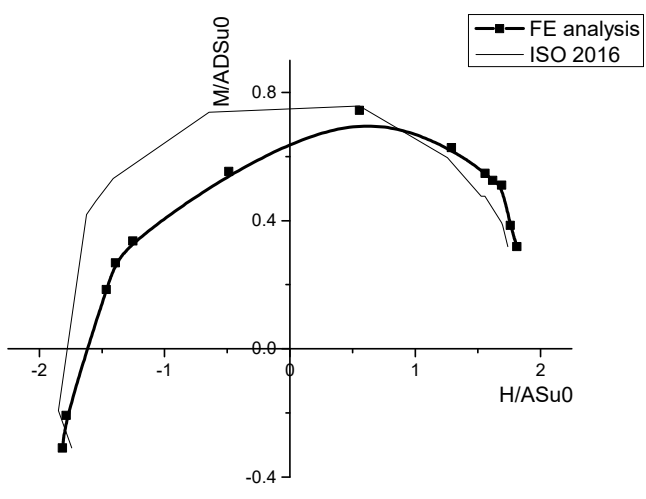

(b)

Fig. 4. Comparison of yield surface: (a) validation of FE model, (b) the coupling effect of HM.

\section{Results}

\subsection{Soil heterogeneity and embedment depth}

The secant rotational stiffness of spudcan is obtained by the stiffness matrix (equation 8) using the finite element data. The ratio of secant rotational stiffness to initial rotational stiffness is the reduction factor, and the initial rotational stiffness can be obtained by the guidelines. As is shown in Fig. 5a, the secant rotational stiffness of spudcans varies uniformly in soils with different soil heterogeneity coefficient $\left(\frac{K D}{S_{u m}}\right)$, which proves that the soil profile does not affect the secant rotational stiffness of spudcans. Similarly, it can be seen from Fig. $5 \mathrm{~b}$ that secant rotational stiffness of spudcans is not affected by embedment depth.

$$
\left\{\begin{array}{c}
\frac{V}{G R^{2}} \\
\frac{H}{G R^{2}} \\
\frac{M}{G R^{3}}
\end{array}\right\}=\left\{\begin{array}{ccc}
K_{V} & 0 & 0 \\
0 & K_{H} & K_{M H} \\
0 & K_{M H} & K_{M}
\end{array}\right\}\left\{\begin{array}{l}
\frac{w}{R} \\
\frac{u}{R} \\
\theta
\end{array}\right\}
$$

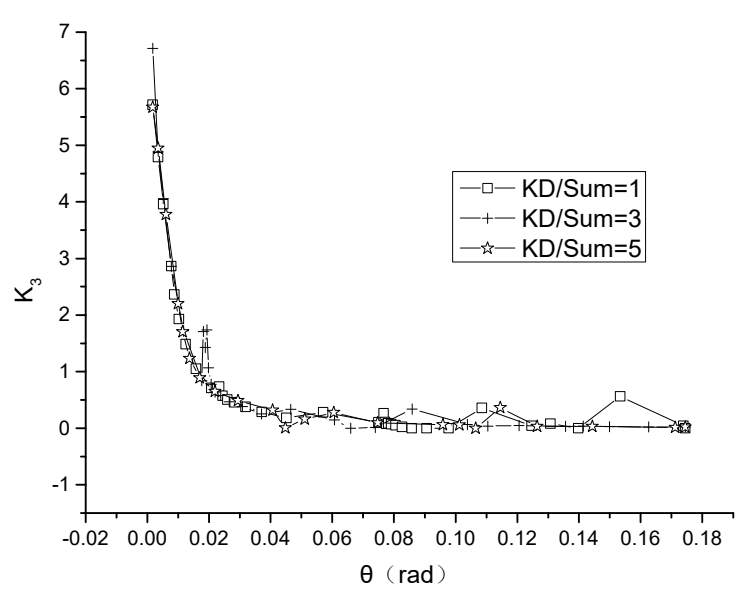

(a)

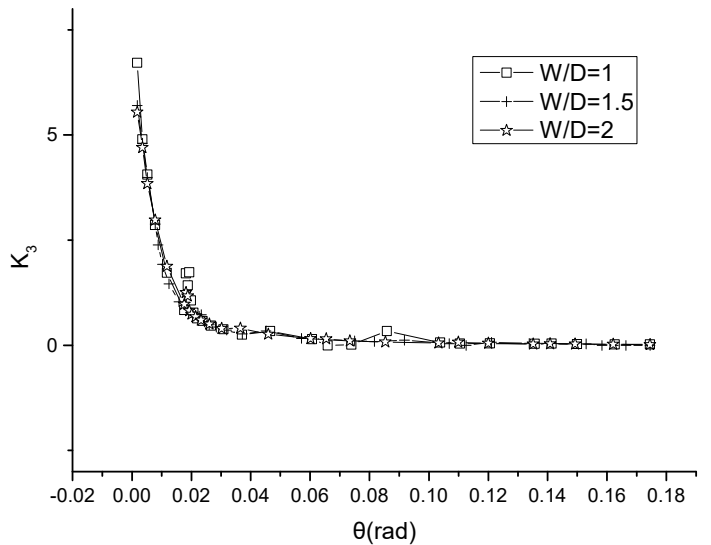

(b)

Fig. 5. Effect of soil heterogeneity and embedment depth on secant rotational stiffness: (a) soil heterogeneity coefficient $\left(\frac{K D}{S_{u m}}\right)$, (b) the embedment depth ratio $\left(\frac{W}{D}\right)$.

\subsection{Failure ratio and reduction factor}

To consider the effect of the coupling of horizontal force and moment on the secant rotational stiffness, a new expression of failure ratio is proposed. The formula is derived from the envelope formula proposed by Zhang and expressed as follows:

$$
r_{f}=\frac{\sqrt{0.9\left(\frac{|M|}{M_{u l t}}\right)^{1.5}+0.9\left(\frac{|H|}{H_{u l t}}\right)^{2.5}-\frac{1.6 e H M}{H_{u l t} M_{u l t}}}}{\sqrt{1-\left(\frac{V}{V_{u l t}}\right)^{2}}} \leq 1
$$

Figure 6 shows the comparison between the reduction factor calculated based on the finite element data under different working conditions and the proposed expression. The expression is obtained through the software "1stopt" and can be expressed below:

$$
f_{r}=\left\{\begin{array}{c}
1-0.35\left(r_{f}+r_{f}^{3}\right), 0 \leq r_{f} \leq 0.75 \\
\left(\frac{2}{r_{f}}-2\right)^{2}, 0.75<r_{f} \leq 1
\end{array}\right.
$$

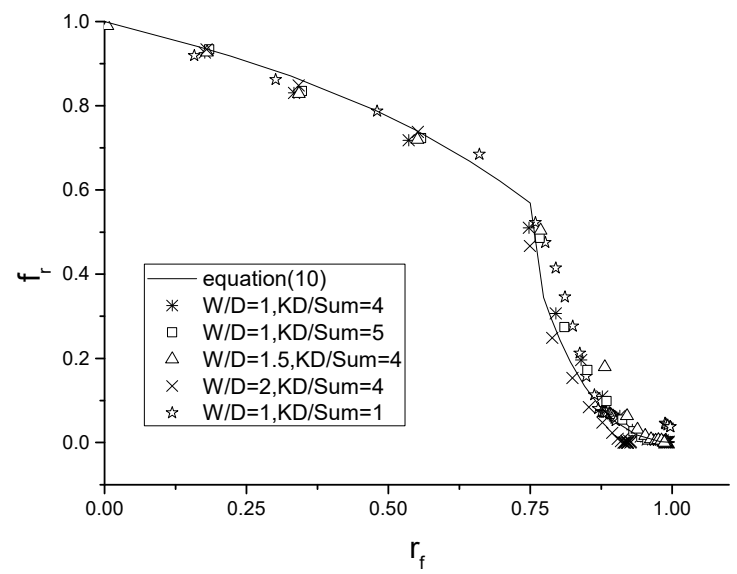

Fig. 6. Validation of expression of failure ratio through data from finite element analyses.

\section{Conclusion}

This paper adopts wished-in-place small strain finite analysis to simulate the load-displacement response of the 
pre-embedded spudcans. It proves that the secant rotational stiffness is not affected by the soil profile and the embedment depth of spudcans, and is only related to the failure ratio. In addition, a new expression of failure ratio and reduction factor is proposed, which takes into account the coupling effect of horizontal force and moment, which may be helpful to predict secant rotational stiffness more reasonably.

\section{References}

1. Arnesen, Knut, and R. Dahlberg. "SOIL/STRUCTURE/INTERACTION ASPECTS FOR JACKUP PLATFORMS." (1988).

2. Hambly, E. C., G. R. Imm, and B. Stahl. "Jackup performance and foundation fixity under developing storm conditions." Offshore technology conference. Offshore Technology Conference, 1990.

3. Cassidy, M. J., C. M. Martin, and G. T. Houlsby. "Development and application of force resultant models describing jack-up foundation behaviour." Marine structures 17.3-4 (2004): 165-193.

4. SNAME Technical \& Research Bulletin 5-5A, Guidelines for Site-Specific Assessment of Mobile Jackup Units, Rev.1. 1991. Jersey City, New Jersey: Society of Naval Architects and Marine Engineers (SNAME).

5. SNAME Technical \& Research Bulletin 5-5A, Guidelines for Site-Specific Assessment of Mobile Jackup Units, Rev. 2. 2002. Jersey City, New Jersey: Society of Naval Architects and Marine Engineers (SNAME).

6. ISO, ISO. "19905-1. Petroleum and Natural Gas Industries-Site-Specific Assessment of Mobile Offshore Units-Part 1: Jack-Ups." ISO: Geneva, Switzerland (2016).

7. SINTEF. 1996. Foundation Fixity Study for Jack-Up Units. Confidential Report STF22 F96660, SNAME OC-7 Panel, Jersey City, New Jersey (30 August 1996)

8. Templeton, J.S. 2007. Spud Can Fixity in Clay, Findings from Additional Work in a Study for IADC. Proc., 11th International Conference on The Jack-up Platform, City University, London, 11-12 September.

9. Zhang, Youhu, et al. "The undrained bearing capacity of a spudcan foundation under combined loading in soft clay." Marine Structures 24.4 (2011): 459-477. 